\title{
Editorial
}

\section{Tolerancia y oscurantismo en el siglo que comienza}

El oscurantismo, sinónimo de un mundo lleno de prejuicios, de injusticias, de fanatismo y de exclusión del saber, ha sido entendido frecuentemente como antítesis del iluminismo. La luz de la modernidad se encendía en medio de la oscuridad medieval y de las demás culturas. El siglo que termina y la sociedad mundial vigente desmienten rotundamente este binomio. La modernidad ha dejado en la oscuridad a la mayor parte de la humanidad y la tolerancia que se reclama en la mayoría de los discursos oficiales y que para los ilustrados era considerada una virtud del estado liberal moderno, un dispositivo público capaz de reconocer dentro del estado-nación las diferencias, es muy ambigua. Es ambigua, constatando tanto lo que los estados ricos, internamente tolerantes, han hecho allende sus fronteras como lo que los estadistas de la mayoría de los países pobres están dispucsıos a tolerar.

La palabra tolerancia es tan socorrida que lo significa prácticamente todo y nada. En principio la tolerancia emana de una autoridad. Se tolera el error y lo que se considera como un mal. Es lo que podemos llamar tolerancia dogmática o intolerancia. En el medioevo llegó a encontrarse un apoyo evangélico en el texto de la parábola de la gran cena: "Sal a los caminos y obliga a la gente a entrar para que se llene mi casa" (Luc., 14, 33) para obligar a sangre y fuego a los herejes y paganos a la aceptación de la fe. En el mejor de los casos la tolerancia dogmática puede llegar a hacer concesiones paternalistas al que no transita por el camino recto. La teorización explícita y laica de la tolerancia se produce con el alba

Tolerancio y oscurontismo en el siglo que comienzo 
del liberalismo. Frente a la intolerancia religiosa que se desencadenó en los siglos XVI y XVI, Locke llegará a afirmar en su Carta sobre la tolerancia de 1689 que en la tolerancia hay el signo más distintivo de la verdadera iglesia. La tolerancia como virtud está en la base de las revoluciones liberales y de la teoría de los derechos civiles y políticos. Después de muchos siglos de guerras de religión se concluyó que muchos valores religiosos, filosóficos, culturales y políticos dependen de la gestión privada y que en su consideración ha de regir el pluralismo. La tolerancia se fue convirtiendo en un derecho humano, el llamado derecho a la libertad de conciencia. Según él, toda persona tiene derecho a vivir de acuerdo con sus propias creencias religiosas y morales. Nadie, ni el Estado, puede coaccionar a quien no sigue un determinado credo religioso. Sin embargo, la tolerancia ilustrada ha sido en el mejor de los casos una especie de indulgencia hacia culturas diversas a la occidental. Todos los hombres son considerados iguales por la razón, pero no todos pueden o saben utilizar la misma y es esta diferencia la que suele justificar nuevas formas de etnocentrismo: la tolerancia ilustrada ha justificado el colonialismo y la exclusión de los otros; ha cerrado los ojos ante la práctica de la esclavitud y ha inventado una nueva versión justificadora de la "servidumbre natural".

En la actualidad la tolerancia es en Europa una de las primeras virtudes que se desean ver inculcadas en los niños. Pero esta tolerancia suele consistir en una especie de desinterés e indiferencia por el otro mientras no nos moleste demasiado. Es más, detrás de esta tolerancia indiferente suelen persistir los clichés más ridículos: las costumbres africanas son bárbaras, los islamistas temibles, los chinos totalitarios, los latinoamericanos irresponsables y así sucesivamente. Cualquier diferencia del otro un poco sostenida es sinónimo de inferioridad. $\mathrm{H}$. Marcuse pone de relieve que en la sociedad postindustrial la tolerancia tiene una función más bien represiva que liberadora al integrar y permitir la expresión formal de las ideas de los grupos dominados, pero no la satisfacción de sus intereses físicos. En los países pobres se ve muy claramente como a menudo la apelación a la tolerancia se convierte en un instrumento de reproducción de las injusticias económicas y sociales. La parte que sufie más la injusticia es tildada de "intolerante" y lanática y los lavorecidos por el sistema al defender la tolerancia suelen también querer negar con ello la existencia de conflictos y de injusticias económicas severas en el orden económico, político y social. De ese modo, la tolerancia formal, propia del liberalismo, suela favorecer más a aquellos a quienes privilegia el orden establecido.

También repunta en los países ricos, ante el continuo flujo de personas de países empobrecidos, lo que podríamos llamar una especie de tolerancia neoracista. Los defensores de este tipo de tolerancia se apropian de los argumentos que la antropología y el relativismo cultural habían utilizado en la década de los 60 para defender la diversidad y la diferencia. El movimiento político que encabeza Le Pen en Francia, por ejemplo, se declara explícitamente no racista y decididamente orien- 
tado a preservar la identidad cultural francesa amenazada por la inmigración. La idea de un "respeto de la diferencia" es utilizada para justificar la expulsión de los inmigrantes. Las otras culturas no son descalificadas explícitamente en tanto culturas inferiores, sino en cuanto culturas inintegrables cuyos portadores constituyen una amenaza de disolución de la supuesta matriz cultural europea, que debe ser preservada. Los conflictos bélicos vigentes, el fundamentalismo y el asesinato de inmigrantes sería fundamentalmente un problema de irrespeto a la identidad cultural. No se postula explícitamente la superioridad cultural de determinados grupos o pueblos respecto a otros, sino simplemente la nocividad de la desaparición de las fronteras, la necesidad de preservar la identidad cultural de cada cual y la incompatibilidad de vivir con gentes que provienen de formas de vida y tradiciones distintas.

Frente a estas diferentes nociones de tolerancia: dogmática, ilustrada, represiva, indiferente y neoracista, podría optarse por dejar de usar un término tan ambiguo y sustituirlo, por ejemplo, por el de respeto a la integridad física y la libertad de conciencia del otro. La ventaja de una reconceptualización del término es que nos permite empalmar directamente con todo un largo debate filosófico-político sobre la tolerancia. Desde una fundamentación zubiriana se podría hablar legítimamente de una tolerancia crítica o activa que reconoce la posibilidad de un diálogo transcultural no por muy difícil imposible. La fuerza de la razón nos lleva a la búsqueda del diálogo, a la crítica correctora y al cultivo de la tolerancia con los demás, pero también a determinar dónde termina la tolerancia y el "respeto a la diferencia" y dónde comienza la indiferencia y la irresponsabilidad por la situación del otro. Esta tolerancia nos saca de muchas aporías que atenazan a movimientos con intenciones liberadoras. Las culturas indígenas, los movimientos antiracistas y diferentes grupos sociales que intentan resistir culturalmente fiente al llamado pensamiento único de la cultura mercantil no luchan sólo por el derecho a la diferencia, sino también por el derecho a la semejanza, a ser tratados en pie de igualdad y con los mismos derechos que todas las demás personas. La reflexión feminista, por ejemplo, se plantea con mucha honestidad como conjugar el respeto de la diferencia con el rechazo de determinadas prácticas culturales. Un caso ejemplar suele ser el de la circuncisión del clítoris en algunas culturas africanas. Por estas prácticas algunas mujeres se ven condenadas a no gozar plenamente del sexo por el resto de sus días. No es raro encontrar mujeres que se sienten orgullosas de haber sido circuncidadas. Las feministas conocen más que nadie las dificultades que encuentran para convencer a las víctimas de todo tipo de prácticas patriarcales que no tienen por qué accptarlas. Pero impedir que esas excisiones sigan produciéndose implica obligar o al menos incitar a esos pueblos a que abandonen sus culturas atávicas. Y, en consecuencia, podría parecer que se transgrede el imperativo de "respetar las diferencias" y que se impone una tradición feminista occidental.

La tolerancia crítica nos fuerza precisamente a ir reprobando este lipo dc prácticas no universalizables. Es preguntándonos qué actuaciones pueden ser 
ejecutadas por cualquiera sin dañar a otros que el universalismo y la tolerancia dejan de ser etnocéntricos. El universalismo al que nos aboca los actos racionales no es la universalidad de unos determinados contenidos o cultura, sino una universalidad que nos lleva a plantear hasta qué punto mis actuaciones, incluso aquellas consideradas más sagradas, son dañinas para otros, aunque estos otros formen parte de culturas ajenas. La tortura, el apedreamiento, o la excisión del clítoris no son prácticas a transformar porque repugnan a la cultura occidental, sino por la pretensión igualitaria, interpersonal y universalizadora de los actos racionales. Del mismo modo, unas formas de vida y una relación con la naturaleza que tienen como resultado la exclusión de millones de personas no son unas prácticas aceptables porque sean preconizadas por la cultura dominante. Aunque este modo de vida "exclusivista" fuera el ideal o el deseo secreto de la mayoría de la humanidad, no resistiría la fuerza de la razón. Ya se ve entonces que la tolerancia activa y solidaria es enormemente incómoda y arriesgada. Nos exige combatir la pereza intelectual, pensar sobre muchas cosas, derechos, conflictos que no están claros en absoluto. Nos exige una especial finura política para respetar las difcrencias comunitarias de lengua, de cultura, de religión y al mismo tiempo el derecho de los individuos a no quedar encerrados en sus diferencias culturales. Sobre todo, nos obliga a comprometernos con los demás. Este "comprometerse" no es un meterse donde no nos llaman, pues de hecho, aún sin querer, ya somos todos unos "entrometidos", sino un hacerse cargo de nuestro entremetimiento.

En un mundo donde ya de hecho nada humano nos es ajeno, sólo una tolerancia crítica que sea intolerable con la miseria, el hambre y los abismos sociales puede no ser sospechosa de etnocentrismo. La tolerancia requiere hoy más que nunca una conciencia cosmopolita de humanidad y una ética universal. El gran miedo que recorre el mundo, más que al extranjero (xenofobia), es miedo al paria (aparofobia), al que no tiene nada ni puede ofrecer nada a cambio, al que no es sujeto de la historia, ni portador de ningún futuro. Los "excluidos" ocupan en la sociedad mundial el lugar que ocupó el antiguo proletario en el interior de los estados curopeos industrializados, pero su situación es mucho más grave. Mientras los obreros eran imprescindibles para los estados industrializados y el capitalismo moderno, los marginados son efectivamente "desechables" y prescindibles. "Tolerancia" querrá decir entonces rechazo de la exclusión, compenetración con los otros, atención a la dignidad de todos, autocrítica del ctnocentrismo aún el que se esconde bajo el reclamo de "respeto a la diferencia". Comprender los hábitos, costumbres y razones del otro no es simplemente aceplar que sea diferente, sino llegarlo a percibir como alguien que nos puede mostrar lormas de vida e ideas mejores que las nuestras y delatar nuestras propias miserias.

En muchos países recién salidos del terror (en el Este y en el Oeste) se proclama la negativa a ocuparse del pasado en nombre de la paz civil y la colerancia, pero ésta es justamente la manera de prolongarlo. La tolerancia crítica 
nos invita a superar el pasado buscando la verdad sobre la propia historia. Es un escándalo que los grandes responsables de los campos de concentración en los países comunistas o que los responsables de crímenes contra la humanidad como los clel asesinato de la comunidad de jesuitas de El Salvador sigan gozando no sólo de libertad, sino de todos los honores y privilegios simbólicos y materiales. No puede hablarse de tolerancia allí donde la verdad, la justicia y la libertad son continuamente pisoteadas. La tolerancia crítica nos invita a intentar hacer un poco de luz en medio de la oscuridad reinante. 